\title{
Quantifying the Cost of Drone-Related Threats in New Zealand
}

\section{Author: Andrew. V. Shelley}

To cite this article: Shelley, A. V. (2021). Quantifying the Cost of Drone-Related Threats in New Zealand. National Security Journal. Published 08 November 2021. doi:10.36878/nsj20211108.03

To link to this artide: https:// doi.org/10.36878/nsj20211108.03

View CrossRef data: https:// search.crossref.org/?q=10.36878\%2Fnsj20211108.03 


\title{
QUANTIFYING THE COST OF DRONE-RELATED THREATS IN NEW ZEALAND
}

\author{
Andrew V. Shelley ${ }^{1}$
}

\begin{abstract}
This article provides initial estimates of the most significant threats from drones in New Zealand. An economic approach is adopted with risks expressed as an expected annual cost, which is consistent with the adoption of a cost-benefit framework for policy development. It will be demonstrated that the expected annual cost of drone misuse are greater than that of a mass shooting, with the risks in the prison system alone exceeding the expected cost of a mass shooting. The expected annual cost of a terror attack exceeds that of the risks to the aviation industry. However current government proposals for registration of drones and licensing of pilots will do little to address the potential threats, which generally - though not exclusively - arise from individuals who have no intention of complying with the law. Indeed, it seems unlikely that the Ministry of Transport's proposed policies will be effective in countering the most significant threats - those policies are likely to cost more than the risk that they might avert. Consequently there is a need to develop a strategy for countering the misuse of drones by those engaged in illegal activities.
\end{abstract}

Keywords: Drones, Unmanned Aerial Systems, risk analysis, terrorism

\section{Introduction}

While drones - more formally known as Unmanned Aerial Systems (UAS) - are acknowledged as having potential to provide considerable economic benefit, like all technology they can be misused, potentially resulting in events such as disruption to air traffic, interruptions to power supplies, injury to people, privacy violations, trespass,

$1 \quad$ Dr Andrew Shelley is Managing Consultant of Andrew Shelley Economic Consulting, and Chief Executive of the drone training school run by Aviation Safety Management Systems Ltd. His research focusses on the regulation of drones and counter-drone systems. He is currently completing a Master of International Security through the Centre of Defence and Security Studies, Massey University. Address for correspondence: Andrew.Shelley@xtra.co.nz. 
and terrorism. All of these events adversely affect wellbeing and security broadly defined. For any given instance of misuse, the misuse could variously be unintentional, negligent, or intentional. Some intentional misuse could result in a criminal harm, such as endangering transport; ${ }^{1}$ negligent and intentional misuse could also result in civil harms such as an interference with the privacy of an individual. ${ }^{2}$ While these three categorisations of unintentional, negligent, and intentional imply different legal responses, from a security perspective the reason why an adverse event occurred does not reduce the impact of that event. The analysis that follows focuses on what might be broadly considered to be security related threats. The legal issues and potential responses to the civil harms of trespass and privacy are not considered here and have been dealt with elsewhere. ${ }^{3}$

The Ministry of Transport (MOT) recently proposed a package of measures such as mandatory education, registration of drones, rule changes, as well as potential for geo-awareness and remote identification of drones at a future time ${ }^{4}$ contending that these proposals will effectively address the misuse of drones. ${ }^{5}$ It is argued here that the MOT's proposals will only be effective for those individuals who choose to comply with the proposed regulations, and will not be effective against criminal harm. New Zealand has seen this same situation arise with firearms reform: law-abiding firearms owners complied with the reforms, while criminal gangs retained prohibited firearms and the pre-existing growth in the level of firearms-related crime has continued unabated. ${ }^{6}$ Furthermore, while providing indicative estimates of the costs of similar regulatory measures in other jurisdictions, the MOT does not provide any quantitative estimate of either the costs of misuse or the purported benefits of the proposed reforms. This article therefore develops quantitative estimates of the cost of misuse of drones, which then provides a foundation to assess whether proposed policy interventions are justified, and whether alternative strategies might be required to counter misuse. Even if the MOT proposals were $100 \%$ effective in preventing these threats, the expected benefits from them will be significantly less than their likely cost.

New Zealand currently has no legislation that enables effective action against drones being utilised in criminal or security-sensitive activities. The Asia-Pacific Economic Cooperation (APEC 2021) Bill would have temporarily remedied this situation for the duration of the APEC 2021 events, with the Bill providing Police with: powers to seize, detain, and take control of a drone; the power to "disable or destroy" a drone "or prevent it from taking off, by any means" (emphasis added) including the use of electronic counter-measures; ${ }^{7}$ powers to require a pilot to land a drone or "stop or limit any activity that may cause a risk to security"; 8 providing Police with powers to request identifying details of a drone pilot. ${ }^{9}$ However, the Bill was withdrawn when the physical visits by dignitaries to New Zealand as part of APEC 2021 were cancelled due to covid-19. In 
September 2021 a new Civil Aviation Bill was introduced to Parliament ${ }^{10}$ that provides a "response officer" with similar powers to those in the APEC 2021 Bill. ${ }^{11}$ It is unclear when the Bill will have passed its second and third readings and pass into law.

This article develops an estimate of the expected annual economic cost of the identified risks. Framing risk as expected annual economic cost has strong linkages with quantitative risk assessment. The assessment of risks based on likelihood and consequence (or severity) is a standard aspect of modern risk assessment, with the interaction between likelihood and consequence often expressed as a risk matrix. ${ }^{12} \mathrm{~A}$ risk matrix provides a shorthand way of establishing the actions that should be taken in respect of a risk, and particularly whether an activity should be able to proceed. However, the validity of the risk matrix approach relies on an objective calibration of the risk levels in the matrix, and does not generally provide an estimate of the level of resources that should be committed to address an identified threat. The economic approach is also concerned with likelihood (or expected frequency of the event) and consequence, but the consequence is expressed in monetary terms if it is possible to do so. The advantage of this approach is that there is a direct indication of the maximum level of resources that should be committed to mitigate or control the risk. If the cost of the controls is less than the expected risk then implementing the controls will make society better off (i.e., it is relatively efficient to implement the controls), but if the cost of controls is greater than the expected risk then the control will make society worse off (and hence it is inefficient to implement the controls).

In the national security context a more nuanced view of risk can be obtained by calculating risk as the product of (a) the probability of a particular threat, (b) the probability of an attack's success given that it occurs, ${ }^{13}$ and (c) the consequence of a successful attack. ${ }^{14}$ This study is concerned not just with an 'attack', which suggests an intent to cause harm or damage, but also with other events that may adversely affect security. For example, an individual who ignorantly or negligently flies in airspace near an airport in a location that causes a hazard to aircraft is not conducting an attack, but they are threatening safety and security. Thus, to better capture the range of potential events I use the term 'threat event' rather than 'attack'.

This paper proceeds as follows: the next section briefly summarises relevant literature on the nature of drone-related risks. The methodology used for quantifying the risks is then described. The methodology assesses the expected frequency of events, using broad but intuitive ranges for how often an event is likely to occur and for how often the event is likely to result in a loss. Cost estimates are provided for each identified risk. The results of the analysis are presented and briefly discussed. The article concludes with some commentary on the results in the context of the potential costs of implementing a drone registration system. 


\section{Threat Identification}

The risk that appears to be of greatest concern to regulators is a collision between a drone and a crewed aircraft carrying passengers. The MOT suggests that a reduction in airspace incursions - which could lead to a mid-air collision - is one of the primary benefits of their proposed reforms. ${ }^{15}$ However, a RAND Corporation study in 2020 identified sixteen other 'threat vectors' from small drones, few of which are directly related to aviation. ${ }^{16}$

Of the sixteen threat vectors identified in the RAND study, the authors of that study identify the highest risk as: intelligence, surveillance, and reconnaissance (ISR); conveyance of items into restricted areas; kamikaze explosive attack (an attack which destroys the drone conveying the explosive); and a Chemical, Biological or Radioactive (CBR) attack. That risk assessment will not necessarily translate directly to New Zealand, with at least some of the threat vectors likely to be less a risk in New Zealand. The discussion that follows here first considers aviation risks, and then considers non-aviation risks. This discussion concludes with a summary of the threats to be evaluated in the risk assessment.

\section{Aviation Risks}

In the event of a collision between an aircraft with people on board and a drone, a range of damage could occur to the aircraft, some of which will be survivable, and some of which might not. Simulation results suggest that a $3.6 \mathrm{~kg}$ drone could fracture the turbine blades of a jet aircraft, rapidly destroying the entire engine. ${ }^{17}$ This is known as an "uncontained engine failure". While such an event is rare, it can cause significant structural damage to an aircraft. Incidents on the ground have resulted in catastrophic fire, ${ }^{18}$ but because they are on the ground such incidents allow people to escape. Uncontained engine failures have also occurred with aircraft in flight, some of which have resulted in fatalities. For example, in 2018 South West Airlines Flight 1380, a Boeing 737, suffered an uncontained engine failure in flight. ${ }^{19}$ Fragments from the engine struck the wing, fuselage, and broke a cabin window. The resulting depressurisation pulled a passenger partially out of the aircraft. That passenger later died, while eight others were injured. Conversely, there are also examples of uncontained engine failures inflight where there have been no fatalities, such as when an Airbus A380 operated by Qantas suffered an uncontained engine failure over Batam Island on 4 November 2010. ${ }^{20}$ Although there was damage to the aircraft, there were no injuries and no fatalities. Another example is United Airlines flight 328, which experienced an uncontained engine failure on 20 February 2021, resulting in no injuries or fatalities. ${ }^{21}$

A study in 2017 considered the effects of a mid-air collision between a drone and a conventional aircraft. ${ }^{22}$ The study reportedly established that airliner windscreens certified against bird strike could be "substantially damaged" in an impact with a drone, but they 
"could retain integrity during impacts with drones up to speeds typically flown during the aircraft landing and later stages of the approach". At higher altitudes and speeds complete structural failure of the windscreen could occur with a 4 kilogram quadcopter. There do not appear to have been any actual collisions between drone and airline windscreens to validate these results. A search of the database of accident statistics maintained by the International Civil Aviation Organisation (ICAO) reveals no accidents involving a collision between a drone and a manned aircraft in the 10 year period 2010-2019. ${ }^{23}$ The Aviation Herald website reports four potential collisions between a drone and an airliner in the period since 2014. Two of those collisions were later reclassified; one was possibly a plastic bag, ${ }^{24}$ while the other saw the aircraft damaged, but this was attributed to a maintenance error and there was no drone involved. ${ }^{25}$ In the remaining two collisions the aircraft suffered only superficial damage. ${ }^{26}$

The 2017 study also analysed the effect of a drone collision with helicopter windscreens not certified against bird strike. Such windscreens were shown to have a "low resistance" to all classes of drone tested, including those as light as $400 \mathrm{~g}$. This potential was confirmed in January 2021 when a Bell Jet Ranger helicopter operated by the Chilean Navy collided with a DJI Mavic drone (less than $1 \mathrm{~kg}$ in weight). ${ }^{27}$ In this incident the pilot was uninjured but a passenger sitting in the rear seat received facial injuries.

The impact against the windscreen of a light aircraft (such as a Cessna 172) is likely to be the same as for a helicopter windscreen, but to date there have been no reported collisions involving a light aircraft windscreen. On 10 August 2021 in Toronto there was a collision between a Cessna 172 operated by a flight training school and a drone operated by local Police. ${ }^{28}$ Elsewhere it was reported that the drone was a DJI Matrice $210,{ }^{29}$ which has a maximum weight of $6.14 \mathrm{~kg},{ }^{30}$ with the actual weight depending on the camera fitted. The aircraft suffered damage to the propeller and the lower nose cone, but was able to safely continue with the landing that was being executed at the time.

The 2017 study also examined drone strike against helicopter tail rotors and concluded that "they would be vulnerable to impacts with all types of drones". ${ }^{31}$ Loss of tail rotor in a helicopter can in some instances result in severe spinning of the helicopter and in any event requires an autorotative emergency landing. ${ }^{32}$ Contrary to these relatively dire warnings, the record suggests that collisions are not necessarily fatal, nor even necessarily result in injuries. On 21 September 2017 a DJI Phantom 4 drone collided with a US Army-operated Sikorsky UH-60M Black Hawk helicopter patrolling restricted airspace imposed during the United Nations General Assembly in New York. ${ }^{33}$ The helicopter suffered a 1.5 inch dent on the leading edge of one of the main rotor blades, but continued flying and the pilot did not notice any change in handling; the Phantom 4 was destroyed. On 4 December 2019 an object collided with an AS-350 B2 helicopter over Los Angeles, damaging the horizontal stabiliser and tail rotor. ${ }^{34}$ The impacting object was not recovered, but laboratory analysis suggests that the object was consistent with the size, shape, and construction of a DJI Phantom drone. Of note, the pilot made 
a precautionary landing only because of the noise of the impact but did not notice any change in handling. In February 2020 the Royal Canadian Mounted Police (RCMP) were utilising an AS350 B3 helicopter and two FLIR SkyRanger drones to monitor a protest over a natural gas pipeline when the helicopter and one of the drones collided. ${ }^{35}$ The helicopter suffered damage to the main rotor, resulting in vibration, so the pilot executed an emergency landing. Subsequent inspection showed superficial damage to the tail rotor. There were no injuries or fatalities. On 18 September 2020 a man in Los Angeles hit the underside of a police helicopter with a drone, ${ }^{36}$ reportedly damaging the helicopter's "nose, antenna and bottom cowlings" ${ }^{37}$ Again there were no injuries or fatalities, and nor is it apparent that the helicopter was unsafe to fly.

Image 1: Matrice 600 drone explodes in failed attempt to assassinate President Maduro. ${ }^{38}$

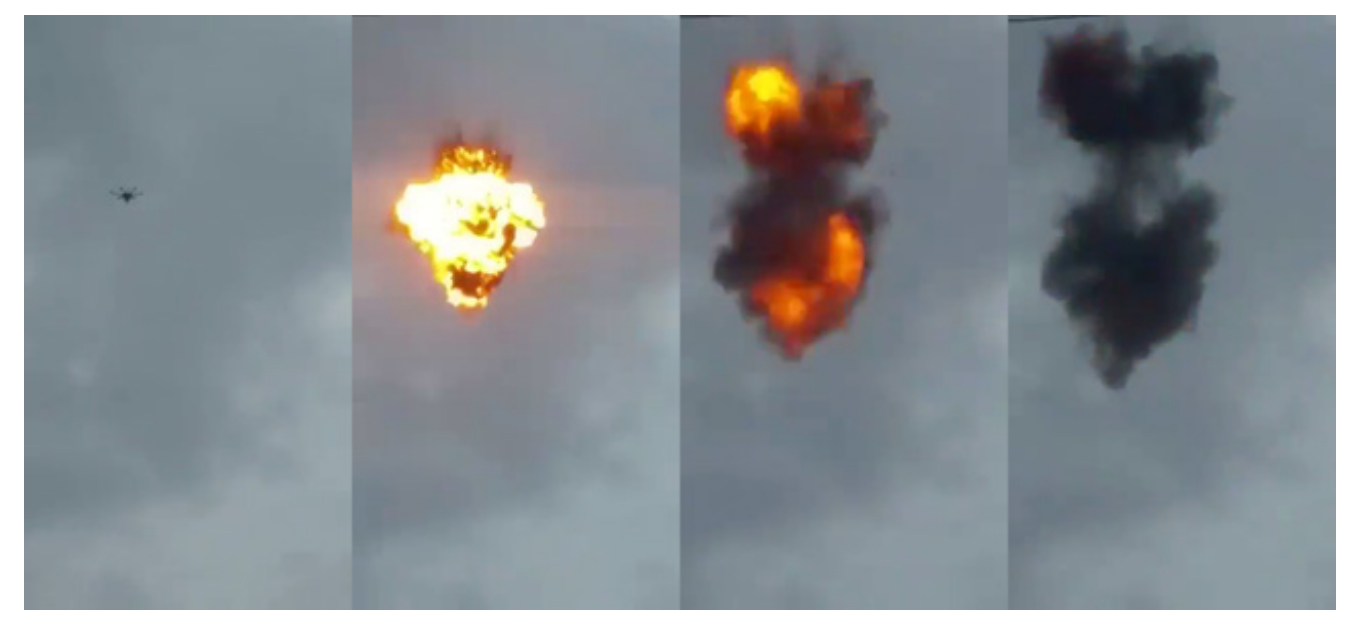

In contrast to the limited number of collisions between a drone and a helicopter, there are many examples of 'air proximity' events where a drone was in close proximity to a helicopter but no collision occurred. For example, on 9 April 2018, operations at RNZAF Whenuapai were suspended when a drone came within $60 \mathrm{~m}$ of a helicopter flying at 3,000ft above ground level. ${ }^{39}$ In October 2018 a drone was reported passing close to the Auckland Westpac Rescue Helicopter. ${ }^{40}$ In the first hour of 2019 a drone came within 10m of the Police 'Eagle' helicopter "at just under 1400 feet" over central Auckland. The helicopter pilot took evasive action and the Eagle helicopter operations were suspended for the rest of the night. ${ }^{41}$ Another helicopter pilot reported encountering three drones over central Auckland while filming the New Year's fireworks display. ${ }^{42}$ Thus, while many near miss events have been reported, there have been very few actual collisions and no fatalities. 


\section{Non-Aviation Risks}

\section{Electric Power Infrastructure}

Electric power infrastructure, particularly overhead power lines and outdoor switch yards, are vulnerable in the event of a drone crash. Careless rather than malicious use of small drones has resulted in power outages of varying severity. In 2015 a drone photographing commercial property in Whangarei, New Zealand, crashed into overhead electricity lines "causing a power cut to about 200 properties and the loss of at least 1000 man-hours of productivity for the businesses affected". ${ }^{43}$ Approximately one month later a drone crashed into power lines in Los Angeles, causing a power outage to approximately 700 people and lasting about 4.5 hours. ${ }^{44}$ In June 2017 a drone crashed into high voltage power lines causing a power outage to approximately 1,600 people for about 2 hours. ${ }^{45}$ In August 2017, a drone crashed into a power line in Moore, Oklahoma, causing a power outage, a small fire, and damaging two cars. ${ }^{46}$

Image 2: Done referred to in Note 47. The article includes a very detailed description and sourcing. ${ }^{47}$

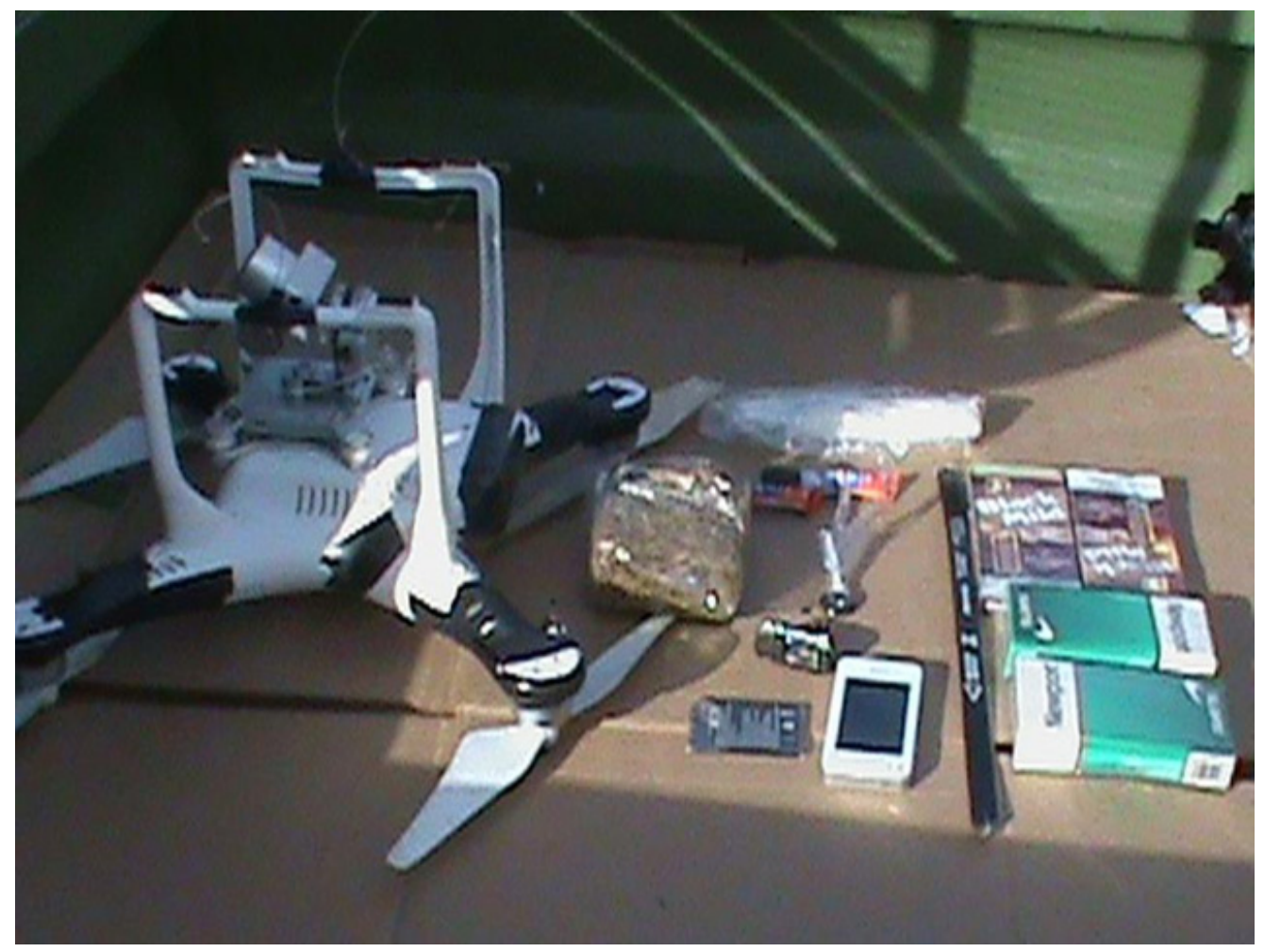




\section{Conveyance of Contraband}

Small drones have been used to deliver contraband - particularly drugs, weapons, and mobile phones - to prisons in the United Kingdom, ${ }^{48}$ the United States, ${ }^{49}$ and Australia. ${ }^{50}$ In the United Kingdom, it was reported that 120 drones were seized flying contraband into prisons over a 23 month period.$^{51}$ In Florida, a DJI Phantom drone was recovered delivering 24 mobile phones to a prison..$^{52}$ In Australia, 177 drone deliveries to Victorian prisons were reported in $2020 .^{53}$ More recently, a drone was reported delivering cigarettes to a quarantine hotel in Queensland, ${ }^{54}$ an activity that also has the potential to enable covid-19 to escape from quarantine into the community.

\section{Intelligence, Surveillance, Reconnaissance (ISR) and Espionage}

As a flying visual surveillance device, drones are ideally suited to being used for ISR. Such ISR could potentially be used for corporate espionage, countersurveillance against law enforcement operations, or by criminals to obtain intelligence prior to burglaries, and it could also compromise national security.

In the national security context, a drone could be used for ISR where imagery is desired that cannot be readily obtained from satellites, without having to negotiate physical access controls. Recently in three separate incidents in Key West, Florida, a total of four Chinese students were arrested after photographing antenna installations and other infrastructure on US military bases. On 26 September 2018, 20 year old Chinese student Zhao Qianli was arrested after photographing buildings and antenna installations at US Naval Air Station Key West. ${ }^{55}$ Fifteen months later, on 26 December 2019, 27 year old Chinese $\mathrm{PhD}$ student Lyuyou Liao was arrested after photographing satellite dishes and antenna on a Key West military installation. ${ }^{56}$ A few days later, on 4 January 2020, Yuhao Wang and Jielun Zhang, both Masters students aged 24, were arrested photographing 'military infrastructure' at US Naval Air Station Key West. ${ }^{57}$ In each of these three cases the individuals had initially bypassed physical access controls, but were nevertheless apprehended. Had they had a drone it would have enabled the imagery to be obtained with a much lower risk of discovery.

Drones have been used to conduct numerous unauthorised flights over French nuclear plants, ${ }^{58}$ raising questions about whether the flights were a pre-cursor to groundbased attack. ${ }^{59}$ While such attacks did not eventuate, these flights highlight the ease with which drones might be used to obtain information on the security at what might be considered "critical infrastructure". Drones can be used for counter-surveillance during law enforcement operations, particularly in locations where it might not be possible to install surveillance cameras. Unsurprisingly, there are few accounts of when drones have been used in this manner, as it is unlikely that law enforcement would want to publicise this fact. However, in 2018 the FBI reported that a criminal gang used drones to disrupt an observation post set up as part of a hostage rescue mission. ${ }^{60}$ 
Similarly, although it is suspected that drones are increasingly used for reconnaissance prior to burglaries, there are few accounts where this has been proven. Suspicions of drones being used for such pre-burglary reconnaissance have been held since 2015, albeit mostly evidence has been circumstantial. ${ }^{61}$. For example, in June 2021 a farm was burgled in Matamata, New Zealand, approximately a week after nearby residents reported a drone flying in the area. ${ }^{62}$ Following recent concerns in North Otago about drones being used to 'scope' homes for burglaries, in early August 2021 a police officer commented publicly that there had never been any cases in New Zealand where the link between drones and burglaries had been confirmed. ${ }^{63}$ Similar comments about the lack of an evidential link between drones and farm burglaries were made by Police in North Wales, United Kingdom, in February 2021. ${ }^{64}$ Conversely, in Oregon in 2019, when reviewing security camera footage after a burglary, the owner of a food-truck saw a drone in close proximity shortly before a burglar cut the locks to the vehicle. ${ }^{65}$ In March 2021 the Sheriff of McLennan County, Waco, announced the arrest of a group of seven people who had "admitted to using a drone to scope out houses, find security cameras around the property and check to see if the victims were at home." ${ }^{\text {. } 66}$

Although there may not be any confirmed links between drones and burglaries in New Zealand, an example that provides a cross-over between ISR (discussed here) and terror attacks (discussed in the next subsection), is Brenton Tarrant's use of a drone to conduct a reconnaissance flight over the Al Noor Mosque some 10 weeks prior to the mass shooting. ${ }^{67}$ However, there is no publicly available information to suggest whether or not the intelligence gained from that reconnaissance aided Tarrant's planning.

\section{Bombing and Terror Attacks}

The Syrian civil war and the subsequent war against ISIS in Syria and Iraq has seen the use of small drones to drop improvised explosives and grenades. ${ }^{68}$ However, the planned use of drones by non-state insurgent groups pre-dates the Syrian civil war. Robert Bunker reports that al-Qaida leaders had considered using drones equipped with improvised explosive devices since before 2001..$^{6}$ These uses of drones highlighted concerns that similar attacks could be conducted in the West. ${ }^{70}$ In August 2018, two drones with on-board explosives were used in an attempt to assassinate President Maduro of Venezuela. ${ }^{71}$ In October of that year, the Director of the FBI stated in testimony before the Senate Homeland Security and Governmental Affairs Committee that: ${ }^{72}$

The FBI assesses that, given their retail availability, lack of verified identification requirement to procure, general ease of use, and prior use overseas, [drones] will be used to facilitate an attack in the United States against a vulnerable target, such as a mass gathering. This risk has only increased in light of the publicity associated with the apparent attempted assassination of Venezuelan President Maduro. 
Underscoring the realistic nature of this threat, in September 2019 a man in Pennsylvania was arrested for allegedly using a drone to drop explosive devices on his ex-girlfriend's house. ${ }^{73}$ In New Zealand, Shelley and Jackson have demonstrated that a DJI Phantom drone can be easily and cheaply adapted to drop an 'Airsoft' compressed air grenade, ${ }^{74}$ which could be replaced with a genuine IED. However, even in its current form, the Airsoft grenade makes a loud noise which could be used to induce panic in a crowd. Crowds have been shown to panic with noises generated from causes as innocuous as a person stepping on and popping a drink bottle ${ }^{75}$ and a falling sign. ${ }^{76}$ This suggests that the simulated device is suitable for use as a diversion device or for causing panic in a crowd.

As an example of dual-use technology associated with drones, incendiary systems exist for starting prescribed fires and back burns for managing wildfires. The Ignis system drops spheres of anti-freeze for the purpose of starting prescribed fires for the management of wildfires. ${ }^{77}$ The spheres are the size of a ping-pong ball and a pre-filled with potassium permanganate. The release mechanism inject the spheres with anti-freeze prior to release, with the spheres catching fire after hitting the ground. A simpler example is the WASP flamethrower with $7.6 \mathrm{~m}$ range. ${ }^{78}$ These commercially available systems have clearly beneficial uses in controlling wildfires, but equally could be weaponised.

Image 3: Flamethrower drone. Source: Throwflame. ${ }^{79}$

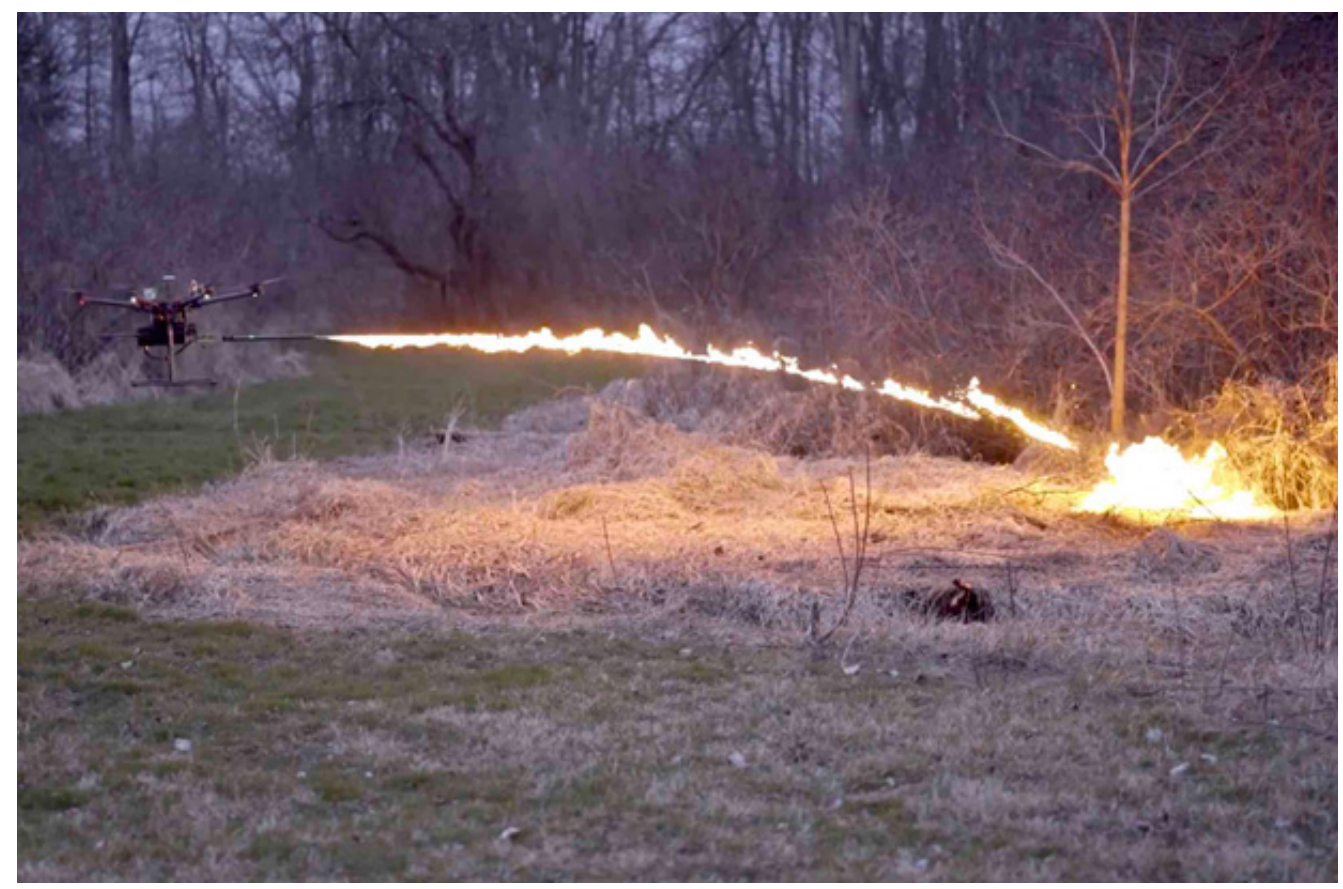


Drones can also be used as the agent for dispersal of biological and chemical weapons. In early 1994 the Japanese cult Aum Shinrikyo attempted to use a remote-control helicopter to deliver the nerve agent sarin against a target, ${ }^{80}$ although the helicopter crashed during testing ${ }^{81}$ and Aum Shinrikyo ultimately decided to release the sarin gas on the Tokyo subway. Modern drones designed to spray agrichemicals are relatively easy to use and are a more practicable delivery method than Aum Shinrikyo's helicopter. The 2020 RAND study includes a hypothetical case study where drones are used to disperse the neurotoxic pesticide phenylsilatrane over the crowd at a Super Bowl game. ${ }^{82}$ Phenylsilatrane does not appear to be readily available in New Zealand, but there are other toxic chemicals which could be manufactured or purchased. Reflecting Aum Shinrikyo's original plans, it is possible that Sarin could be manufactured and then dispersed by drones, although precursor chemicals are heavily regulated in New Zealand. Alternatively, it would be more straightforward to manufacture ricin and disperse that via a drone. Another possible chemical payload is 1080 solution, which could be purchased with a Controlled Substances Licence, or alternatively obtained via burglary. Magnesium Phosphide pellets could be dispensed via a drone with a topdressing attachment, decomposing on contact with water to produce phosphine, which is a highly flammable and acutely toxic gas. ${ }^{83}$ Drones capable of agrichemical dispersal have a wide price range, but lower quality drones that might not last more than a few months in commercial spraying operations are readily available via mail order from China for less than NZ \$5,000.

\section{Summary}

Based on the discussion above, the drone threats likely to be of particular relevance in New Zealand are:

- Collision with aircraft, causing damage or fatalities;

- Using explosives to damage or disrupt power supply and oil \& gas facilities'

- Delivery of IEDs, either at a mass event or against a specific target;

- Incendiary attack, especially at a mass event;

- Causing disruption to airports;

- Causing panic by dropping inert or noise-maker devices;

- Counter-surveillance during Police operations such as raids related to organised crime and drugs such as methamphetamine;

- Surveillance prior to or during burglary;

- Surveillance in areas of commercial or national security sensitivity;

- Creating a diversion to enable other direct action to occur;

- Delivery of contraband to secure sites including prisons and quarantine facilities;

- Delivery of electronic listening devices to otherwise impossible to reach locations; and

- Chemical or biological attack at mass event. 


\section{Methodology}

\section{General Approach}

The risk arising from a specific threat can be expressed as: ${ }^{84}$

$$
\text { Risk }=\text { Frequency } \times P(\text { Success }) \times \text { Consequence }(1)
$$

where Risk is the expected annual cost of the threat, Frequency is the number of threat events expected to happen annually, $P$ (Success) is the probability of a threat event's success given that it occurs, and Consequence is the estimated cost of a successful threat event in dollars.

On the basis of news reports, it is possible to assess the relative frequency of events if not the actual frequency. For the analysis presented here, frequency is assessed as daily, weekly, monthly, annually, or once-per-decade. To allow for uncertainty in these estimates assumed ranges are shown in Table 1. As an example, an event with a frequency of "monthly" is expected to occur twelve times per year, but has a range of between three and 21 times per year. In all cases a rectangular (uniform) distribution is assumed, so that the expected number of events is the simple average of the minimum and maximum.

Table 1: Events per Year based on Relative Frequency.

\begin{tabular}{|l|r|r|r|}
\hline Frequency & \multicolumn{1}{|c|}{ Minimum } & \multicolumn{1}{c|}{ Maximum } & \multicolumn{1}{|c|}{ Expected } \\
\hline Decade & 0.025 & 0.175 & 0.1 \\
\hline Annual & 0.25 & 1.75 & 1 \\
\hline Monthly & 3 & 21 & 12 \\
\hline Weekly & 13 & 91 & 52 \\
\hline Daily & 91.25 & 638.75 & 365 \\
\hline
\end{tabular}

Estimating the probability of success is necessarily subjective, but again it is possible to rely on news reports to obtain an indication of relative likelihood for many of the events. Recognising the subjective nature of these estimated probabilities I utilise four broad categories of 'low' (zero to 20 percent), 'medium' (above 20 percent but less than 50 percent), 'high' (above 50 percent but less than 80 percent), and 'almost certain' (above 80 percent). Again a rectangular distribution is assumed.

The combination of the number of threat events expected to happen annually (Table 1) and the probability of the threat event's success yields the number of successful events per year shown in Table 2. The expected number of successful events per year is the 
product of the expected number of threat events and the expected probability of success. Although the expected number of threat events and the expected probability of success are both assumed to be the mid-point of a rectangular distributions, the expected number of successful events per year will be in the lower half of the range of successful events. Consider, for example, the first row of Table 2 which shows a daily event with a medium probability of success. The minimum estimate of the number of successful events is 91.25 threat events $\mathrm{x} 20$ percent success $=18.25$ successful events. The maximum estimate of the number of successful events is 638.75 threat events $\mathrm{x} 50$ percent success $=319.375$ successful events. The midpoint of this range is 168.8 successful events per year. ${ }^{85}$ However, the expected number of successful events is 365 threat events $\mathrm{x} 35$ percent success $=127.75$ successful events per year, ${ }^{86}$ which is less than the midpoint of the range. Relying on the mid-point of the successful events range overstates the number of successful events per year.

Table 2: Expected number of successful events per year based on the frequency of threat events and probability of success.

\begin{tabular}{|l|l|c|c|}
\hline \multirow{2}{*}{ Frequency } & \multirow{2}{*}{ P(Success) } & \multicolumn{2}{|c|}{ Successful Events per Year } \\
\cline { 2 - 4 } & & Range & \multicolumn{2}{|c|}{ Expected } \\
\hline daily & medium & $18.25-319.38$ & 127.75 \\
\hline weekly & almost certain & $10.4-91.0$ & 46.8 \\
\hline daily & low & $0.0-127.8$ & 36.5 \\
\hline weekly & high & $6.5-72.8$ & 33.8 \\
\hline weekly & medium & $2.6-45.5$ & 18.2 \\
\hline monthly & almost certain & $2.4-21.0$ & 10.8 \\
\hline monthly & high & $1.5-16.8$ & 7.8 \\
\hline weekly & low & $0.0-18.2$ & 5.2 \\
\hline monthly & medium & $0.6-10.5$ & 4.2 \\
\hline monthly & low & $0.0-4.2$ & 1.2 \\
\hline annual & almost certain & $0.2-1.75$ & 0.9 \\
\hline annual & high & $0.13-1.4$ & 0.65 \\
\hline annual & medium & $0.05-0.88$ & 0.35 \\
\hline annual & low & $0.00-0.35$ & 0.10 \\
\hline decade & almost certain & $0.02-0.175$ & 0.09 \\
\hline decade & high & $0.013-0.14$ & 0.065 \\
\hline decade & medium & $0.005-0.088$ & 0.035 \\
\hline decade & $0.000-0.035$ & 0.010 \\
\hline
\end{tabular}




\section{Consequence: The Cost of Fatalities and Injuries}

Consequences from a threat event could include the costs of responding to the event, costs of delay or disruption, lost production, damage to equipment or aircraft, fatalities and injuries. To aid comparison across the different consequences, all of these consequences can be expressed in dollar terms. For fatalities it is appropriate to use the value of a statistical life (VOSL) of $\$ 4.42$ million per fatality as used by MOT for estimating the social cost of death and injury from transport accidents across transport modes. ${ }^{87}$ The same source also estimates the social cost of serious injuries from road crashes as $\$ 467,700$, and minor injuries as $\$ 25,300$, both of which include estimates of the value of loss of life quality, loss of economic productivity, and the use of medical and other resources. ${ }^{88}$

\section{Estimates by type of Threat}

\section{Threats to Aviation}

Risks to aviation include disruption of flights, collision with an aircraft causing fatalities, and collision with an aircraft causing damage to the aircraft. In the event of drone-related disruptions it appears that NZ airports are closed for a period of approximately 15 minutes. ${ }^{89}$ Preston Davies and Murray estimate the Value of Travel Time (VoTT) per hour for domestic air travellers in NZ as "NZ\$57.02 for personal travel and NZ\$81.30 for business travel" (2015/16 dollars). ${ }^{90}$ Applying an "unexpected delay" factor of 3.5 VoTT for personal travel and 5.6 VoTT for business travel, and assuming a ratio of $50 \%$ personal and $50 \%$ business travel then produces a delay cost of $\$ 327.43$ per passenger per hour. For the 2019 calendar year Auckland Airport reported a total of 9,534,492 domestic passenger movements, ${ }^{91}$ which equates to an average 1,687 domestic passenger movements per hour (assuming a 15.5 hour day). A single 15 minute delay therefore has average delay costs of $\$ 138,000$. Actual costs could be twice this at peak time, and will also include additional fuel burn for delayed aircraft. For this analysis, the low estimate of costs is assumed $\$ 138,00$ per event; the high estimate of costs is assumed $\$ 276,000$ per event.

If a drone damages an airline engine or cockpit windscreen, then the aircraft may be required to return to the departure airport or - if sufficiently far en-route - divert to a different airport and passengers may be delayed for several hours. Alternative road transport may be required, which could easily be in the order of a 2-3 hour road trip. Costs will therefore include the delay cost for the passengers and the cost of replacing the damaged aircraft component. A reasonable upper bound estimate of the cost of lost travel time can be derived by assuming an Airbus A-320 operated by Air New Zealand with a full load of 171 passengers, ${ }^{92}$ delayed for 3 hours. Applying the delay cost of $\$ 327.43$ per passenger per hour produces a total delay cost of $\$ 167,972$. Given the results of the 2017 study discussed earlier, ${ }^{93}$ it is possible that damage could occur to 
an airline windscreen in the event of a frontal impact. One public source estimates the cost of a Boeing 737 windscreen as "around [US]\$26,000". ${ }^{44}$ It is reasonable to assume a cost of a similar order of magnitude for the windscreen of an A320. If an engine is damaged and requires replacing, with the cost of a partially used replacement engine for the A-320 in the order of US $\$ 1.75 \mathrm{~m}$ to US $\$ 3 \mathrm{~m},{ }^{95}$ which at an exchange rate of 0.7 US$\mathrm{D}: \mathrm{NZD}$ is NZ\$2.5 to NZ\$5.0m. Note that it is unlikely that both a cockpit windscreen and an engine would be damaged, with a drone likely to impact either the windscreen or the engine. However, in this analysis these two events are treated as independent, which allows for the possibility of multiple drones with one hitting the windscreen and one ingested into the engine. Costs will differ from this for a small aircraft. Smaller aircraft with from 4 to 6 people on board may be less likely to have survivors in the event of a crash. The cost of an aircraft loss is estimated as US\$165,000 for a Cessna 172. ${ }^{96}$

As discussed earlier, a crash is unlikely for an airliner, with modern twin-engine aircraft being designed to fly on one engine and examples of aircraft being able to continue to fly with an uncontained engine failure. However, there have been examples already mentioned where the uncontained engine failure has ruptured the fuselage of the aircraft and a passenger has died. Treating engine failure and fatalities as independent events allows for the possibility, although remote, that both outcomes might occur.

The last remaining estimate required for threats to aviation is that of frequencies for the various scenarios considered. On review of the evidence presented the likely frequency of an event that could cause disruption to flights is monthly, with a medium probability of success. The likely frequency of a collision with an aircraft causing fatalities is judged to be a once-per-decade event with a low probability of success. Collision with an aircraft causing engine damage and collision with an aircraft causing windscreen damage are both judged to be an annual event with a low probability of success. Given that these last two events are not documented to have ever occurred anywhere in the world, it could be argued that the assumed frequency is too high; this is perhaps mitigated by the assumed low probability of success, and will also result in a conservatively high estimate of cost.

\section{IEDs, Incendiaries, and CBR}

A modification to the above estimate of frequency is required where there are closely related events. In particular, given the documentary record, it appears that there is a low likelihood of a drone attack either at a mass event or as a specifically targeted event. Using the scale in Table 2, the frequency is assessed as likely to be once per decade. However, this once-per-decade event could be an IED attack causing fatalities, it could be an IED attack resulting in injuries, it could be an incendiary attack, or it could be a CBR attack. Counting each of these potential types of attack as a once-per-decade event then results in in one of these events occurring, on average, once every 2.5 years and thus greatly overstates the risk. 
To better account for the risk an event tree is used as shown in Figure 1. From the top node of the tree an attack either occurs or it does not occur. An attack occurs once-perdecade, so the annual frequency is $F=0.1$ events. The attack is either a CBR attack, IED attack, or incendiary attack. Assume that due to the relative difficulty of obtaining the chemicals for a CBR attack there is a 10 percent probability of the attack being a CBR attack. In the event of an IED attack, the result could be some combination of fatalities, injuries, and disruption. All three could occur simultaneously, and allow for a separate probability of success for each. Give the current documentary record, the probability of success is low for fatalities, medium for injuries, and high for disruption.

Figure 1. Event tree for IED, Incendiary, and CBR attack.

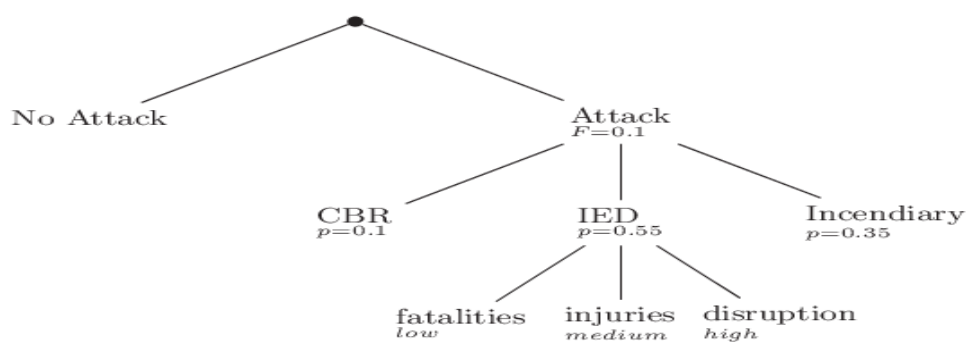

\section{Interruption to Electric Power Supply}

As discussed earlier in this article, disruption to electricity supply by small drones is an event that has occurred, both in New Zealand and elsewhere. All of the examples discussed were unintentional, but more significant power outages could arise with a well-planned intentional attack. The economic cost of an interruption to electric power supply is measured by the "Value of Lost Load" (VOLL). Transpower estimates values of VOLL for individual substations, calculated from the actual electrical load at the substation and estimated VOLL by customer type, time of day, and season. The estimated per-substation VOLL ranges from $\$ 11.00 / \mathrm{kWh}$ for a substation that has a primarily residential load to $\$ 43.00 / \mathrm{kWh}$ for a substation that has a primarily agricultural load. ${ }^{97}$ MBIE reports that for the calendar year 2020 average electricity demand was 18,484 kilowatt hours (kWh) per "Installation Control Point" (ICP), across all customer types. ${ }^{98}$ A property will have a minimum of one ICP per separately metered tenant. For an outage of one hour the average quantity of electricity not consumed over that period is $1,214.55 \mathrm{kWh} / \mathrm{ICP}$. If a one-hour outage affects 200 ICPs then the total foregone consumption is $242,911 \mathrm{kWh}$ and the economic cost of this lost load is between $\$ 2.7$ mil- 
lion and \$10.4 million. Using residential average annual consumption of 7,230 kWh/ ICP and the low estimate of VOLL, the cost reduces to $\$ 1.0$ million. Using commercial average annual consumption of $48,717 \mathrm{kWh} / \mathrm{ICP}$ and the high estimate of VOLL, the cost increases to $\$ 27.5$ million. Given these estimates, the low estimate of the cost of a loss of supply event is set at \$1.0 million and the high estimate is set at \$27.5 million.

\section{Panic at mass events}

Panic at a mass event has the potential to result in multiple fatalities and injuries. At a mass event panic could arise from an IED attack, an incendiary attack, dropping a noise maker device for the specific purpose of causing panic, and using a spray drone to disperse a chemical agent or biological toxin. Hsieh et al. analyse 215 reported human stampede events from 1980 to 2007, developing fatality and injury rates for a subset of 133 events that had estimated numbers of participants. ${ }^{99}$ The fatality rate for developed countries had a median of 0 fatalities per 100,000 participants, with an inter-quartile range of 0 to 7 fatalities. The median injury rate for developed countries was 39 injured persons per 100,000 participants, with an inter-quartile range of 21 to 57 injured persons. To convert these rates to an absolute number of fatalities and injuries requires an estimate of the crowd size. A capacity crowd at Eden Park is approximately 50,000, ${ }^{100}$ which implies 0 to 3.5 fatalities and 11.5 to 28.5 injured persons in the event of a panic-induced stampede.

\section{Diversion allowing other action}

Creating a diversion to enable other direct action to occur is a location- and situation-specific event. We might hypothesise that such an event could occur in response to a Police raid on organised crime or suspected terrorist facilities. Alternatively, such an event might be linked to terrorist action itself. In the first instance, such diversion may simply create space for the criminal(s) to escape, but to count as a diversion that allows other "direct action" to occur necessarily implies action that at a minimum will cause material damage and potentially an increased probability of loss of life. This study assumes that the likely consequence ranges from escape of the criminal or material damage, which is arbitrarily valued at a loss of $\$ 50,000$ through to the fatality of one law enforcement officer. These estimates are subjective and may be able to be improved with further analysis.

\section{Delivery of Contraband to Prisons}

The final drone-related risk modelled is the delivery of contraband to prisons. Contraband would typically be weapons, drugs, or mobile phones. When the drone reaches the target delivery area it could land and wait for someone to detach the payload, or with less risk of being discovered, the payload could be dropped from the drone using a mechanism such as that described by Shelley and Jackson. ${ }^{101}$ The type of harm caused depends on the contraband. Weapons could be used to harm, and potentially kill, ei- 
ther fellow inmates or guards. Drugs will likely allow drug addiction to be perpetuated, increasing the likelihood of recidivism on release. Drugs may also contribute to prison violence. Mobile phone use can range from benign activities such as communicating with family, through to intimidation of individuals outside prison and arranging criminal activities. While straightforward to describe, these forms of harm are hard to value. This study separately estimates the cost of fatal and nonfatal harm. One event per month is assumed that might result in a single fatality, but a low probability of success is also assumed, so there is an estimated 1.2 fatal events per year. For non-fatal harm the likely consequence ranges from an arbitrary minimum of zero through to $\$ 0.4 \mathrm{~m}$, which is the approximate social cost of a single serious injury. Attempted drone deliveries could occur weekly at any given prison, so non-fatal harm is estimated to occur daily across the prison network, but again with a low probability of success. Note that contraband could also be delivered to other secure sites, such as airside at an airport, but such a scenario seems less likely than delivery to a prison.

\section{Mass Shooting}

As a point of comparison, an estimate of the risk of a mass shooting event is given. The low number of fatalities is taken from the typical threshold to count as a mass shooting. ${ }^{102}$ In comparison, there were 14 fatalities in the Aramoana massacre, ${ }^{103}$ and 35 fatalities and 19 injured in the Port Arthur Massacre. ${ }^{104}$ The high number of fatalities is taken from the Christchurch mosque shooting. No allowance is made for the increased risk of retaliatory or copycat attacks following a mass shooting, nor for the cost of reductions in civil liberties that may follow from the desire of politicians to be seen to be 'doing something.' ${ }^{105}$

\section{Results \& Discussion}

Table 3 presents the results of the qualitative risk analysis and the quantitative estimate of the expected annual cost. Annual cost is calculated as the product of the per-event cost and the relevant number of successful events per year from Table 2. As with the number of threat events per year and the probability of success, a rectangular distribution for the per-event cost is assumed. As discussed earlier, the expected annual cost lies below the mid-point of the annual cost range.

The total expected annual cost from all quantified drone threats is $\$ 15.3$ million, which is almost twice the expected annual cost of $\$ 8.5$ million for a mass shooting. The $\$ 15.3$ million does not include the non-quantifiable threats of surveillance in areas of commercial or national security sensitivity, delivery of electronic listening devices, and surveillance prior to or during burglary. The $\$ 8.5$ million also does not include the costs of firearms crime other than a mass shooting. 
It is apparent that most drone threats have a relatively low expected annual cost, to the extent that they can be quantified. Of the quantifiable risks, the largest cost is from the delivery of contraband to prisons, with an aggregate expected annual cost of $\$ 10.0$ million. Contraband deliveries that might result in a fatality due to a riot, stabbing, or similar are assumed to occur monthly but with a low probability of success there is less than one successful event per year and an expected annual cost of \$2.7 million. Contraband deliveries that result in other harm such as serious injuries (which could potentially arise from drug-related harm) are assumed to be attempted daily but with a low probability of success have an expected annual cost of $\$ 7.3 \mathrm{~m}$. If such deliveries were only attempted weekly across the prison system then the expected annual cost reduces from $\$ 7.3$ million to $\$ 1.0$ million. This in turn reduces the total expected annual cost from all quantified drone threats to $\$ 9.1 \mathrm{~m}$, similar to that of a mass shooting.

Threats to aviation have an aggregate expected annual cost of $\$ 1.5$ million, with the largest component of that being disruption of flights. Disruption of flights is a result of choices made to mitigate a perceived risk, but this analysis suggests that the perception might not be accurate. Since the start of 2014 there have only been two recorded collisions between airliners and drones worldwide, with only superficial damage to the airliner in both cases. While the low rate of collisions may be because aircraft have been diverted or placed in holding patterns on a number of occasions, the parameter estimates assumed in the current study result in a cost estimate from collisions that is slightly exceeded by the cost of diversions.

IED, incendiary, and CBR attacks are the classic "terror" threats from drones, and in aggregate have an expected annual cost of $\$ 1.0 \mathrm{~m}$. These threats are thus marginally more costly than disruption to air travel. However, the results also suggest that it might not be necessary for a would-be terrorist to go to the trouble and effort of using explosives, incendiaries, or chemical agents: given the assumed parameters, the expected annual cost of a panic event is a similar order of magnitude at $\$ 1.1 \mathrm{~m}$. In aggregate, this potential to use drones for terror attacks or terror-inducing attacks has an aggregate expected annual cost of $\$ 2.1 \mathrm{~m}$, some 44 percent higher than the aggregate cost of aviation-related risks. New Zealand currently has no means of directly countering these threats.

Two other risks of significance are disruption to electric power supplies $(\$ 0.9 \mathrm{~m})$ and creating a diversion to allow other direct action to occur $(\$ 0.8 \mathrm{~m})$. Disruption to power supplies will always be a potential outcome, even with no intent. Just as the potential for a car crashing into a power pole always remains as a potential "threat", the potential for a drone to accidentally crash into powerlines and cause an outage may also be a threat that cannot be eliminated. The potential for a diversion is a more significant problem, possibly resulting in increased likelihood of a criminal escaping, or injury or fatality to law enforcement or other personnel. 
Table 3: Quantitative Risk Assessment.

\begin{tabular}{|c|c|c|c|c|c|}
\hline Threat & Freq. & $\begin{array}{c}\mathrm{P} \\
\text { (Success) }\end{array}$ & Consequence & $\begin{array}{l}\text { Cost per } \\
\text { Event }\end{array}$ & $\begin{array}{c}\text { Risk (Expected } \\
\text { Annual Cost, } \\
\text { \$m) }\end{array}$ \\
\hline \multicolumn{6}{|l|}{ Aviation } \\
\hline Disruption of flights & monthly & medium & $\begin{array}{l}\text { aircraft in holding } \\
\text { pattern, diversions, } \\
\text { cancellations }\end{array}$ & $0.1-0.3$ & $0.9[0.1-2.9]$ \\
\hline $\begin{array}{l}\text { Collision with aircraft causing } \\
\text { fatalities }\end{array}$ & decade & low & $\begin{array}{l}\text { 1-6 dead, destruction } \\
\text { of aircraft }\end{array}$ & $4.7-31.2$ & $0.2[0.0-1.1]$ \\
\hline $\begin{array}{l}\text { Collision with aircraft causing } \\
\text { engine damage }\end{array}$ & annual & low & $\begin{array}{l}\text { engine replacement; } \\
\text { delays from diversion } \\
\text { or return }\end{array}$ & $2.7-5.2$ & $0.4[0.0-1.8]$ \\
\hline $\begin{array}{l}\text { Collision with aircraft causing } \\
\text { windscreen damage }\end{array}$ & annual & low & $\begin{array}{l}\text { windscreen damage; } \\
\text { delays from diversion } \\
\text { or return }\end{array}$ & $0.1-0.4$ & $0.0[0.0-0.1]$ \\
\hline \multicolumn{6}{|l|}{ IED, Incendiary \& CBR Attack } \\
\hline IED attack causing fatalities & decade & low & 1-5 dead & 4.4-22.1 & $0.1[0.0-0.4]$ \\
\hline IED attack causing injuries & decade & medium & $1-10$ injured & $0.5-4.7$ & $0.0[0.0-0.2]$ \\
\hline IED attack causing disruption & decade & high & $\begin{array}{l}\text { Same effect as panic } \\
\text { event }\end{array}$ & $5.4-28.8$ & $0.6[0.0-2.2]$ \\
\hline $\begin{array}{l}\text { Incendiary attack at mass } \\
\text { event }\end{array}$ & decade & medium & $\begin{array}{l}\text { 1-10 injured from } \\
\text { incendiary, damage to } \\
\text { facilities, panic }\end{array}$ & $5.9-33.6$ & $0.2[0.0-1.0]$ \\
\hline CBR attack & decade & low & $\begin{array}{l}\text { 1-20 injured, 1-10 } \\
\text { fatalities }\end{array}$ & $4.9-53.6$ & $0.0[0.0-0.2]$ \\
\hline \multicolumn{6}{|l|}{ Critical infrastructure } \\
\hline $\begin{array}{l}\text { Disruption to electricity } \\
\text { supply }\end{array}$ & decade & high & power cuts, repair costs & $1.0-27.5$ & $0.9[0.0-3.9]$ \\
\hline Attack on oil \& gas facility & decade & medium & $\begin{array}{l}\text { oil/gas release; possible } \\
\text { fire; possible injures, } \\
\text { fatalities; repair costs }\end{array}$ & $0.0-4.9$ & $0.1[0.0-0.4]$ \\
\hline \multicolumn{6}{|l|}{ Other } \\
\hline $\begin{array}{l}\text { Causing panic by dropping } \\
\text { inert or noise-maker devices } \\
\text { at a mass event }\end{array}$ & decade & high & $\begin{array}{l}\text { 0-3.5 fatalities, } 11.5- \\
28.5 \text { injured persons }\end{array}$ & $5.4-28.8$ & $1.1[0.1-4.0]$ \\
\hline $\begin{array}{l}\text { Creating a diversion to } \\
\text { enable other direct action to } \\
\text { occur }\end{array}$ & annual & medium & $\begin{array}{l}\text { Escape of criminals, } \\
\text { material damage, injury } \\
\text { to or fatality of law } \\
\text { enforcement officer }\end{array}$ & $0.1-4.4$ & $0.8[0.0-3.9]$ \\
\hline $\begin{array}{l}\text { Delivery of contraband to } \\
\text { prison }\end{array}$ & monthly & low & $\begin{array}{l}\text { Fatality of guard or } \\
\text { inmate }\end{array}$ & $0.0-4.4$ & $2.7[0.0-18.6]$ \\
\hline $\begin{array}{l}\text { Delivery of contraband to } \\
\text { prison }\end{array}$ & daily & low & $\begin{array}{l}\text { Serious injury or equiv- } \\
\text { alent }\end{array}$ & $0.0-0.4$ & $7.3[0.0-51.1]$ \\
\hline Total all drone threats & & & & & $15.3[0.2-91.9]$ \\
\hline Comparison: mass shooting & decade & high & $\begin{array}{l}\text { 5-51 deaths; 0-40 } \\
\text { injuries }\end{array}$ & $17.7-244.1$ & $8.5[0.2-34.2]$ \\
\hline
\end{tabular}




\section{Conclusion}

Regulatory reforms recently proposed by MOT include measures such as mandatory education, registration of drones, rule changes, as well as potential for geo-awareness and remote identification of drones at a future time. ${ }^{106}$ However, unless remote identification is non-bypassable, registration and remote identification will do little to solve the problem of errant drones, particularly for those individuals who are intentionally misusing them. When remote identification is either absent or can be easily bypassed then registration is only effective if it is possible to easily identify the drone operator without registration. ${ }^{107}$ If the drone operator cannot be readily identified in the absence of registration and remote identification, then there is a strong incentive to bypass any registration scheme that is introduced. Furthermore, most significant costs estimated in this analysis are associated with illegal activities. It is highly unlikely that individuals deliberately embarking on illegal activity will choose to comply with regulations intended to make it easier to identify either them or their drones.

It seems likely, therefore, that the implementation of the MOT's proposals will do little, if anything, to reduce the risks estimated in this article. It is possible that the proposals will be effective in reducing the risks to the aviation system and inadvertent disruptions to power supplies, which have an aggregate expected annual cost of only \$2.4 million. The MOT notes that Australia incurred costs of NZ $\$ 7.7$ million in a single year for its registration and pilot accreditation system, whereas the United Kingdom incurred NZ $\$ 4.4$ million. Consequently, even if the proposals were $100 \%$ effective in preventing these threats, the expected benefits of the MOT's proposals will be significantly less than the likely cost.

Thus, regardless of whether the MOT's proposals are implemented, most of the threats identified in Table 3 will continue to exist, and the expected annual costs of those threats will remain unchanged. Of particular significance is the estimated $\$ 10$ million of expected annual cost from delivery of contraband to prisons. This suggests that the Department of Corrections, which is responsible for New Zealand's prisons, should be empowered to take action to counter drones. Similarly, it seems highly unlikely that the MOT's proposals will do anything to stop terrorist activity and there is a need for major events to be able to stop rogue drones. The potential for drones to be used to collect intelligence on high technology facilities also suggests that the operators of those facilities should be empowered to take appropriate action to counter drones. The counter-drone provisions proposed in the Civil Aviation Bill may potentially address these threats, but that is outside the scope of this article.

The cost estimates in this article are likely to be lower bound estimates of the cost of misuse of drones. First, some areas of cost have not been quantified, such as those associated with ISR, surveillance, and espionage. Second, the analysis focusses on security-related risks and therefore does not include broader costs such as trespass and priva- 
cy violations. In addition, some of the cost estimates are based on subjective estimates - for example, the cost of harm of delivery of contraband to prisons - and would benefit from a more detailed study in their own right.

On the basis of the estimates developed in this analysis, there is a clear need for entities such as the Department of Corrections and major events providers to be able to take appropriate action to counter drones. Conversely, it seems unlikely that the MOT's proposed policies will be effective in countering the most significant threats, and on the basis of information presented by the MOT, those policies are likely to cost more than the risk that they might avert. The results of this analysis suggest that, rather than focussing on policies to address inadvertent misuse of drones by law-abiding drone operators, there is a strong case to develop a strategy for countering the misuse of drones by those engaged in illegal activities. 
1 Crimes Act 1961, 'New Zealand Statutes', 1961, S 270. Available at http://legislation.govt.nz/act/ public/1961/0043/latest/whole.html.

2 Privacy Act 2020, 'New Zealand Statutes', 2020, S 69. Available at http://www.legislation.govt.nz/ act/public/2020/0031/latest/whole.html.

3 Andrew V. Shelley, 'Proposals to address Privacy Violations and Surveillance by Unmanned Aerial Systems', Waikato Law Review 24, no. 1 (2016): 142-170.

4 New Zealand Ministry of Transport, Enabling Drone Integration: Discussion Document, technical report (6 April 2021) . Available at https://www.transport.govt.nz/assets/Uploads/Discussion/EnablingDroneIntegration.pdf.

5 MOT, Enabling Drone Integration: Discussion Document.

6 Omitting the outlier event of the 15 March 152019 mosque shooting, total firearms-related offences in New Zealand were 901 in calendar year 2018, 1,050 in 2019, and 1,141 in 2020. There were 647 offences in the six months to the end of June 2021, suggesting a possible total of 1,294 offences for 2021. See, NZ Police, Firearms Information Summary as at 5 Jul 2021, technical report (5 July 2021) . Available at https://www.police.govt.nz/sites/default/files/publications/firearms-information-summary-5july2021.xlsx.

7 S 82, Asia-Pacific Economic Cooperation (APEC 2021) Bill, 'Government Bill', 14 November 2019. Available at http:/www.legislation.govt.nz/bill/government/2019/0187/8.0/LMS180841.html.

8 S 82, Asia-Pacific Economic Cooperation (APEC 2021) Bill.

9 S 87, Asia-Pacific Economic Cooperation (APEC 2021) Bill.

10 Civil Aviation Bill, Bills (proposed laws), New Zealand Parliament. Available at https://www.parliament.nz/en/pb/bills-and-laws/bills-proposed-laws/document/BILL_115765/civil-aviation-bill.

11 Sections 318-323, Civil Aviation Bill, Bills (proposed laws), New Zealand Parliament. Available at https://www.legislation.govt.nz/bill/government/2021/0061/latest/whole.html\#LMS348840.

12 Nenad Kovačević, Aleksandra Stojiljković, and Mitar Kovač, 'Application of the matrix approach in risk assessment', Operational Research in Engineering Sciences: Theory and Applications 2, no. 3 (11 December 2019): 55-64. Available at https://www.oresta.rabek.org/index.php/oresta/article/view/32.

13 Barry Charles Ezell et al., 'Probabilistic Risk Analysis and Terrorism Risk', Risk Analysis 30, no. 4 (2010). DOI:10.1111/j.1539-6924.2010.01401.x.

14 Henry H. Willis et al., Estimating Terrorism Risk, technical report (Center for Terrorism Risk Management Policy, RAND Corporation, 2005). Available at https://www.rand.org/content/dam/rand/pubs/ monographs/2005/RAND_MG388.pdf.

15 MOT, Enabling Drone Integration: Discussion Document.

16 Bradley Wilson et al., Small Unmanned Aerial System Adversary Capabilities, technical report (Homeland Security Operational Analysis Center, RAND Corporation, 2020). Available at https://www. rand.org/pubs/research_reports/RR3023.html.

17 S Mackay, 'Engineering researchers seek remedies for threat posed by drones to commercial airliners'. Available at October 2015, http://www.vtnews.vt.edu/articles/2015/10/102815-engineering-jetenginedronestrike.html. See also S Wasserman, 'Personal Drones Getting Sucked into Jet Engines Could Be Disastrous', November 2015. Available at http:/www.engineering.com/DesignSoftware/DesignSoftwareArticles/ArticleID/10914/Personal-DronesGetting-Sucked-into-Jet-Engines-Could-Be-Disastrous.aspx.

18 "Engine parts pierced protective case in British Airways 777 fire in Las Vegas", 11 September 2015. Available at https://www.seattletimes.com/business/boeing-aerospace/engine-parts-found-on-runwayfrom-british-airways-777-fire/.

19 National Transportation Safety Board, 'Southwest Airlines engine incident: 5/3/2018 Investigative Update', 3 May 2018. Available at https://www.ntsb.gov/investigations/Pages/DCA18MA142.aspx.

20 Australian Transportation Safety Bureau, In-flight uncontained engine failure Airbus A380-842, VHOQA, overhead Batam Island, Indonesia, 4 November 2010, Aviation Occurence Investigation AO-2010089, Final (Australian Transportation Safety Bureau, June 2013).

21 National Transportation Safety Board, United Airlines Flight 328 Boeing 777 Engine Incident: Investigative Update, technical report (5 March 2021). Available at https:/www.ntsb.gov/investigations/ Pages/DCA21FA085.aspx. 
22 Small Remotely Piloted Aircraft Systems (drones) Mid-Air Collision Study, technical report (Department for Transport, Military Aviation Authority, and British Airline Pilot's Association, July 2017). Available at https://www.gov.uk/government/publications/dronesand-manned-aircraft-collisions-test-results.

23 International Civil Aviation Organisation, https://www.icao.int/safety/iStars/Pages/Accident-Statistics.aspx.

24 “"Drone' that hit British Airways jet above Heathrow Airport 'could be plastic bag"”, Evening Standard, 21 April 2016. Available at https:/www.standard.co.uk/news/london/suspected-drone-that-hitbritish-airways-jet-above-heathrow-airport-could-be-plastic-bag-a3230791.html.

25 Simon Hradecky, 'Incident: Aeromexico B738 at Tijuana on Dec 12th 2018, radome damage on final approach', Aviation Herald, 31 May 2019. Available at http://avherald.com/h?article=4c185005\&opt=0.

26 Simon Hradecky, 'Incident: Argentinas B738 at Buenos Aires on Nov 11th 2017, drone strike', Aviation Herald, 13 November 2017. Available at http://avherald.com/h?article=4b0e37e6\&opt=0. See also Simon Hradecky, 'Incident: Austral E190 at Buenos Aires on Dec 21st 2018, collision with Unmanned Aerial Vehicle inflight', Aviation Herald, 17 December 2019. Available at http://avherald.com/h?arti$\mathrm{cle}=4 \mathrm{c} 2909 \mathrm{fd} \&$ opt $=0$.

27 Nicolás Parra, 'Accidente aéreo: drone impacta a helicóptero de la Armada en pleno vuelo y hiere a tripulante ', biobiochile.cl, 23 January 2021, https://www.biobiochile.cl/noticias/nacional/region-de-valparaiso/2021/01/23/accidente-aereo-drone-impacta-a-helicoptero-de-la-armada-en-pleno-vuelo-e-hiere-a-tripulante.shtml.

28 "York police drone collides with plane approaching Buttonville Airport, TSB investigating", City News, 21 August 2021, https://toronto.citynews.ca/2021/08/20/york-police-drone-midair-collision-buttonville-airport/.

29 Aviation Safety Network, 'ASN Wikibase Occurrence \# 266897'. Available at https://aviationsafety. net/wikibase/266897.

30 DJI, https://www.dji.com/nz/matrice-200-series/info\%5C\#specs.

31 Small Remotely Piloted Aircraft Systems (drones) Mid-Air Collision Study.

32 Federal Aviation Administration, Helicopter Flying Handbook, FAA-H-8083-21A (U.S. Department of Transportation, Federal Aviation Administration, 2012), pages 11-16.

33 National Transportation Safety Board, Aviation Incident Final Report, technical report, Incident Number: DCA17IA202A, Midair collision (14 December 2017). Available at https://app.ntsb.gov/ pdfgenerator/ReportGeneratorFile.ashx?EventID=20170922X54600\&AKey=1\&RType=HTML\&IType $=\mathrm{IA} \% \mathrm{EF} \% \mathrm{BB} \% \mathrm{BF}$.

34 National Transportation Safety Board, Aviation Incident Final Report, technical report, Incident Number: DCA20IA034A, Midair collision (4 December 2019). Available at https://web.archive. org/web/20200707230459/https://app.ntsb.gov/pdfgenerator/ReportGeneratorFile.ashx?Even$\mathrm{tID}=20191205 \mathrm{X} 95005 \& \mathrm{AKey}=1 \& \mathrm{RType}=$ Final\&IType=IA.

35 "RCMP drone was flying at wrong altitude when it collided with helicopter in B.C.", Vertical, 18 June 2020. Available at https://verticalmag.com/news/rcmp-drone-flying-wrong-altitude-collided-helicopter/.

36 "Man pleads guilty after drone hits LAPD helicopter, conviction 1st of its kind", NBC News, 16 January 2021. Available at https://www.nbcnews.com/news/us-news/man-pleads-guilty-after-dronehits-lapd-helicopter-conviction-1st-n1254365.

37 "FBI arrests man after drone hits LA police helicopter", AP News, 20 November 2020. Available at https://apnews.com/article/los-angeles-arrests-burglary-hollywood-0a8d8385flc0685701d594fc4a4bef8f.

38 The C-Drone Review, https://c-drone-review.news/en/2018/08/08/weaponized-c-drones-in-venezuela-assassination-attempt/ image: https://c-drone-review.news/wp-content/uploads/2018/08/cesguar. png. Image is comprised of screen captures from CaracasNews24: https://twitter.com/CaracasNews24/ status/1026193542274867208. Video is also provided in Bellingcat report, footnote 70 in revised article: https://www.bellingcat.com/news/americas/2018/08/07/drones-attack-maduro-caracas/.

39 "Drone nearly hits Air Force helicopter at Whenuapai Air Force Base", NZ Herald, 9 April 2018. Available at https:/www.nzherald.co.nz/nz/drone-nearly-hits-air-force-helicopter-at-whenuapai-airforce-base/OYWKLV74DBQEZEF2HUCPMVVCPY/. 
40 "Auckland Westpac Rescue Helicopter in near miss with drone", NZ Herald, 23 October 2018. Available at https:/www.nzherald.co.nz/nz/auckland-westpac-rescue-helicopter-in-near-miss-withdrone/B32I36HWNNPRYRSKPQHMM5Y4HA/.

41 New Zealand Police, 'Drone incident with Police Eagle helicopter', 1 January 2019. Available at http://www.police.govt.nz/news/release/drone-incident-police-eagle-helicopter.

42 "Pilot: drone owners playing with lives", Radio New Zealand, 3 January 2019. Available at https:// www.radionz.co.nz/news/national/379349/pilot-drone-owners-playing-with-lives.

43 "Operator investigated after drone hits lines", The Northern Advocate, September 2015. Available at https://www.nzherald.co.nz/northern-advocate/news/operator-investigated-after-drone-hits-lines/7JX762TKEII3UCMKZ4DZ37VG4I/.

44 "Drone downs power lines in Hollywood, hundreds affected for a few hours", ARS Technica, October 2015. Available at https://arstechnica.com/tech-policy/2015/10/drone-downs-power-lines-inhollywood-hundreds-affected-for-a-few-hours/. See also "Drone knocks out power to hundreds of West Hollywood residents", Los Angeles Times, 27 October 2015. Available at http://www.latimes.com/local/ lanow/la-me-ln-drone-power-west-hollywood-20151027-story.html.

45 "Drone crash knocks out power to 1,600 in Mountain View", Mercury News, 10 June 2017. Available at http://www.mercurynews.com/2017/06/09/drone-crash-knocks-out-power-to-1600-in-mountainview/.

46 "Drone Causes Power Outage In Moore", News9.com, 28 August 2017. Available at http://www. news 9.com/story/5e349a3d527dcf49dad81db8/drone-causes-power-outage-in-moore.

47 https://www.reuters.com/article/us-oklahoma-prison-idUSKCNOSL22220151027.

48 "Drone carrying drugs, hacksaw blades crashes at Oklahoma prison", Reuters, October 2015. Available at https://www.reuters.com/article/us-oklahoma-prison-idUSKCNOSL22220151027 .

49 "Drone that makes getting drugs and illicit mobile phones in Strangeways 'as easy as ordering Chinese' crashes inside prison yard", Mail Online, 10 November 2015. Available at https://www.dailymail. co.uk/news/article-3310299/Drone-makes-getting-drugs-illicit-mobile-phones-Strangeways-easy-ordering-Chinese-crashes-inside-prison-yard.html.

50 "Victorian prison armed with new technology to crackdown on increase in drone-delivered contraband", 9News, 9 August 2021. Available at https:/www.9news.com.au/national/victorian-prisons-equipped-with-new-technology-to-crackdown-on-drone-smuggling/530fl f5e-73ab-4de9-b92512 ceaa06b16f

51 "Drones are caught flying drugs or mobile phones into jail every five days: Specialist squad has seized 120 devices since the start of 2016 and convicted 17 people", Daily Mail Australia, 22 November 2017. Available at https:/www.dailymail.co.uk/news/article-5105841/Drones-caught-taking-drugs-prison-five-days.html.

52 Rochisha Shukla, Bryce E. Peterson and KiDeuk Kim, Contraband and Interdiction Strategies in Correctional Facilities, technical report (Urban Institute, February 2021). Available at https://www. urban.org/sites/default/files/publication/103619/contraband-and-interdiction-strategies-in-correctional-facilities_0.pdf.

53 Note 48 above.

54 "Drone spotted delivering cigarettes to hotel quarantine on Gold Coast", 9 News, 9 July 2021.

Available at https://www.9news.com.au/national/hotel-quarantine-woman-caught-receiving-illegal-delivery-of-cigarettes-from-drone/ac777220-b441-46df-9793-8076f3383918.

55 "Chinese student sentenced to one year for taking photos of Key West Naval base", Miami Herald, 5 February 2019. Available at https://web.archive.org/web/20190205233914/https://www.miamiherald. com/news/local/article225540955.html.

56 "Chinese national arrested for taking photos at Naval Air Station in Key West", Miami Herald, 27 December 2019. Available at https://web.archive.org/web/20200103033620/https://www.miamiherald. com/news/local/article238749763.html.

57 "Amid rising spy concerns, 2 more Chinese students held after shooting photos at base", Miami Herald, 7 January 2020. Available at https://www.miamiherald.com/news/local/community/florida-keys/ article239010873.html.

58 "French government on high alert after unexplained drone flights over nuclear power stations", Independent, November 2014. Available at http://www.independent.co.uk/news/world/europe/frenchgovernment-on-high-alertafter-unexplained-drone-flights-over-nuclear-power-stations-9850138.html. 
59 "Drones: The Threat to Nuclear Plants", Newsweek, December 2014. Available at http://www.newsweek.com/drones-threat-nuclear-plants294458.

60 “A Criminal Gang Used a Drone Swarm to Obstruct an FBI Hostage Raid”, Defense One, 3 May 2018. Available at https://www.defenseone.com/technology/2018/05/criminal-gang-used-drone-swarmobstruct-fbi-raid/147956/.

61 "Burglars use drone helicopters to target homes", The Telegraph, 18 May 2015. Available at http:// www.telegraph.co.uk/news/uknews/crime/11613568/Burglars-use-drone-helicopters-to-identify-targehomes.html.

62 “Burglars go hi-tech: 'suspicious' drone spotted days before farm shed burglary”, Stuff, 2 July 2021. Available at https://www.stuff.co.nz/national/crime/125610799/burglars-go-hitech-suspicious-dronespotted-days-before-farm-shed-burglary.

63 "Fear drones 'scoping' homes in North Otago", Otago Daily Times, 2 August 2021. Available at https://www.nzherald.co.nz/nz/fear-drones-scoping-homes-in-north-otago/BK5TSAA7UMSR625CR3QDMVWFLY/.

64 "Thieves using drones to scope farms, police warn", Farmers Weekly, 3 February 2021. Available at https://www.fwi.co.uk/news/crime/thieves-using-drones-to-scope-farms-police-warn.

65 "Owners: Thieves used drones to burgle food carts", KOIN 6, 1 October 2019. Available at https:// www.koin.com/news/crime/owners-thieves-used-drones-to-burgle-food-carts/

66 "Sheriff: Waco-area burglary ring used spy drone", Waco Tribune-Herald, 1 March 2021. Available at https://wacotrib.com/news/local/crime-and-courts/sheriff -waco-area-burglary-ring-used-spy-drone/ article c721eb7c-7af6-11eb-9a44-23609624a788.html.

67 "Exclusive: Christchurch gunman flew a drone over mosque weeks before March 15 shooting", Newshub, 23 July 2020. Available at https://www.newshub.co.nz/home/new-zealand/2020/07/exclusivechristchurch-gunman-flew-a-drone-over-mosque-weeks-before-march-15-shooting.html.

68 "ISIS drones are attacking U.S. troops and disrupting airstrikes in Raqqa, officials say", Washington Post, June 2017. Available at https://www.washingtonpost.com/news/checkpoint/wp/2017/06/14/isisdrones-are-attacking-u-s-troops-and-disrupting-airstrikes-in-raqqa-officials-say/. See also "The Drones of ISIS", Defense One, January 2017. Available at http://www.defenseone.com/technology/2017/01/dronesisis/134542/.

69 Robert J Bunker, Terrorist and Insurgent Unmanned Aerial Vehicles: Use, Potentials, and Military Implications, technical report (Strategic Studies Institute, U.S. Army War College, August 2015) . Available at https://www.hsdl.org/?view\&did=786817.

70 "ISIS planning to use toy helicopters as bombing drones fear security chiefs", Mirror, July 2015. Available at http://www.mirror.co.uk/news/world-news/isis-planning-use-toy-helicopters-6119888.

71 NicholasWaters, Did Drones Attack Maduro in Caracas?, technical report (Bellingcat,

7 August 2018) . Available at https:/www.bellingcat.com/news/americas/2018/08/07/dronesattack-maduro-caracas/.

72 Christopher Wray, 'Threats to the Homeland: Statement Before the Senate Homeland Security and Governmental Affairs Committee', 10 October 2018. Available at https://www.fbi.gov/news/testimony/ threats-to-the-homeland-101018.

73 "Accused Slate Belt bomb-maker used drone to drop explosives on ex-girlfriend's home, prosecutor says", The Morning Call, 17 September 2019. Available at https://www.mcall.com/news/breaking/ mc-nws-accused-bangor-bomber-used-drone-drop-explosives-20190917-kj5kr75acjdxxc2jin5yhjniy4-story.html.

74 Andrew V. Shelley and Chris Jackson, Proof of Concept for a Drone-Borne Improvised Explosive Device, Working Paper (16 November 2020).

75 "Panic in Central Park Caused by 'Popping' Drink Bottle, Not Fallen Barrier or Gunshots", New York Times, 29 September 2018. Available at https://www.nytimes.com/2018/09/29/nyregion/central-park-panic-global-citizen-festival.html.

76 "Utah mall evacuates a panicking crowd after the sound of a falling sign was mistaken for gunfire", Salt Lake Tribune, 8 August 2019. Available at https:/www.sltrib.com/news/2019/08/07/utah-mall-evacuates/.

77 Drone Amplified, ‘Department of the Interior Recognises Ignis Technology’, 17 January 2019.

Available at https://droneamplified.com/department-of-the-interior-recognizes-ignis-technology/. 
78 Throwflame, 'TF-19WASP Flamethrower Drone Attachment', https://throwflame.com/products/ flamethrower-drone-kit/.

79 https://throwflame.com/products/flamethrower-drone-kit/. Image url: https://d2p4va2bfxy5el.cloudfront.net/wp-content/uploads/2019/07/09154859/Drone-flamethrower.jpg

80 Tim Ballard et al., Chronology of Aum Shinrikyo's CBW Activities, technical report (James Martin Center for Nonproliferation Studies, Middlebury Institute of International Studies at Monterey, 2001) . Available at http://www.nonproliferation.org/chronology-of-aum-shinrikyos-cbw-activities/.

81 Robert J Bunker, Terrorist and Insurgent Unmanned Aerial Vehicles: Use, Potentials, and Military Implications, technical report (Strategic Studies Institute, U.S. Army War College, August 2015) . Available at https://www.hsdl.org/?view\&did=786817.

82 Bradley Wilson et al., Small Unmanned Aerial System Adversary Capabilities, technical report (Homeland Security Operational Analysis Center, RAND Corporation, 2020) . Available at https://www. rand.org/pubs/research reports/RR3023.html.

83 PharmoChem Company, Safety Data Sheet: Magtoxin, Revision 1.2, 20 May 2020, https://pestoff. co.nz/wp-content/uploads/2021/03/Magtoxin.pdf.

84 Adapted from Barry Charles Ezell et al., 'Probabilistic Risk Analysis and Terrorism Risk', Risk Analysis 30, no. 4 (2010), https://doi.org/10.1111/j.1539-6924.2010.01401.x and Henry H. Willis et al., Estimating Terrorism Risk, technical report (Center for Terrorism Risk Management Policy, RAND Corporation, 2005), https://www.rand.org/content/dam/rand/pubs/monographs/2005/RAND MG388.pdf. 85 The midpoint of the range is calculated as $(18.25+319.375) / 2=168.8125$ successful events.

86 The midpoint of the number of threat events is $(91.25+638.75) / 2=365$ threat events per year. The midpoint of the probability of success is $(20+50) / 2=35$ percent.

87 New Zealand Ministry of Transport, Social cost of road crashes and injuries 2020 update: June 2020, technical report (June 2021) . Available at https://www.transport.govt.nz/assets/Uploads/SocialCost-of-Road-Crashes-and-Injuries-2020_final.pdf.

88 New Zealand Ministry of Transport, Social cost of road crashes and injuries 2020 update: June 2020.

89 "Drone spotted 30 metres from plane at Auckland Airport", NZ Herald, 28 April 2021. Available at https://www.nzherald.co.nz/nz/drone-spotted-30-metres-from-plane-at-auckland-airport/JLFJA4D6OLRHIAHHRZO3W3LVXY/.

90 Selena He Preston Davies and Kieran Murray, Asymmetric impact on consumers from underinvestment by airports - an indicative view, technical report, Report prepared for New Zealand Airports Association (Sapere Research Group, 17 March 2016) . Available at https://comcom.govt.nz/_data/ assets/pdf_file/0012/61221/NZ-Airports-submission-attachment-Sapere-Asymmetric-impact-on-consumers-from-underinvestment-by-airports-17-March-2016.pdf.

91 Auckland Airport, Monthly traffic updates (2021), https://corporate.aucklandairport.co.nz/news/ publications/monthly-traffic-updates.

92 Air New Zealand, “Airbus A320 (NZ Domestic)”, https:/www.airnewzealand.co.nz/seatmap-airbus-a320-171d.

93 Small Remotely Piloted Aircraft Systems (drones) Mid-Air Collision Study, technical report (Department for Transport, Military Aviation Authority, and British Airline Pilot's Association, July 2017) . Available at https://www.gov.uk/government/publications/dronesand-manned-aircraft-collisions-test-results .

94 Mike Arnot, "How Much Do Airplane Parts Cost? From \$4 Amenity Kits to \$1,000,000 First-Class Seats", 14 July 2019, https://thepointsguy.com/news/how-much-do-airplane-parts-cost-from-4-amenitykits-to-1000000-first-class-seats/.

95 Aircraft Commerce, 'The economics of using repaired and serviceable parts in engine maintenance', no. 120 (2018): 43-51. Available at https://aeronorway.no/wp-content/uploads/2019/01/Aero-NorwayAC-Nov.pdf.

96 Aircraft Cost Calculator, 'CESSNA 172R Price and Operating Costs'. Available at https://www. aircraftcostcalculator.com/AircraftOperatingCosts/327/Cessna+172R.

97 Transpower New Zealand Ltd, Value of Lost Load Study, technical report (November 2018). Available at https://www.transpower.co.nz/sites/default/files/publications/resources/Value\%20of\%20Lost\%20 Load\%20\%28VoLL\%29\%20Study\%20-\%20June\%202018.pdf. 
98 Ministry of Business, Innovation and Employment, "Electricity graph and data tables", https://www. mbie.govt.nz/assets/Data-Files/Energy/nz-energyquarterly-and-energy-in-nz/Electricity.xlsx.

99 Yu-Hsiang Hsieh et al., 'Epidemiological Characteristics of Human Stampedes', Disaster Medicine and Public Health Preparedness 3, no. 4 (December 2009): 217-223. DOI:10.1097/DMP. 0b013e3181c5b4ba.

100 Eden Park, “Our Park”, https://edenpark.co.nz/about-eden-park/.

101 Andrew V. Shelley and Chris Jackson, "Proof of Concept for a Drone-Borne Improvised Explosive Device", Working Paper (16 November 2020).

102 Rosanna Smart and Terry L. Schell, 'Mass Shootings in the United States', Gun Policy Research Review, 15 April 2021. Available at https://www.rand.org/research/gun-policy/analysis/essays/mass-shootings.html.

103 "Flashback: The Aramoana massacre", Stuff, 15 November 2014. Available at https://www.stuff. co.nz/national/crime/63230292/flashback-the-aramoana-massacre.

104 Samara McPhedran, ‘Australian Mass Shootings: An Analysis of Incidents and Offenders', Journal of Interpersonal Violence 35, nos. 19-20 (12 June 2017): 3939-3962. DOI:10.1177/0886260517713226. 105 Note that a reduction in political civil liberties is associated with a reduction in terrorism. See, for example, M.A. Rubin and R.K. Morgan, 'Terrorism and the Varieties of Civil Liberties', Journal of Global Security Studies 6, no. 3 (3 August 2020). DOI:10.1093/jogss/ogaa032.

106 New Zealand Ministry of Transport, Enabling Drone Integration: Discussion Document, technical report (6 April 2021). Available at https://www.transport.govt.nz/assets/Uploads/Discussion/EnablingDroneIntegration.pdf.

107 Andrew V. Shelley, 'Essays in the Regulation of Drones and Counter-Drone Systems' (PhD diss., Victoria University of Wellington, May 2020) . Available at http://researcharchive.vuw.ac.nz/handle/10063/8900. 